\title{
1 Satellite Remote Sensing: Ocean Color
}

2

\author{
P. Jeremy Werdell* and Charles R. McClain \\ NASA Goddard Space Flight Center, Greenbelt, MD, USA \\ * Corresponding author: jeremy.werdell@nasa.gov
}

\section{Introduction}

The term 'ocean color' refers to the spectral composition of the visible light field that emanates from the ocean. The color of the ocean depends on the solar irradiance spectrum, atmospheric conditions, solar and viewing geometries, and the absorption and scattering properties of water and the substances that are dissolved and suspended in the water column, e.g. phytoplankton and suspended sediments [Mobley, 1994]. Water masses whose reflectance is determined primarily by absorption by water and phytoplankton are generally referred to as 'Case 1' waters. In other situations where scattering is the dominant process, or where absorption is dominated by substances other than phytoplankton or their derivatives the term 'Case 2 ' is applied [Morel and Prieur, 1977].

The primary optical variable of interest for remote sensing purposes is the water-leaving radiance, that is, the subsurface upwelled radiance (light moving upwards in the water column) propagating through the air-sea interface, which does not include the downwelling irradiance (light moving downward through the atmosphere) reflected at the interface. To simplify the interpretation of ocean color, measurements of the water-leaving radiance are normalized by the surface downwelling irradiance to produce reflectance spectra, which provide an unambiguous measure of the ocean's subsurface optical signature [Gordon and Morel, 1983]. Clear open-ocean reflectances have a spectral peak at blue wavelengths because water absorbs strongly in the near-infrared and scatters blue light more effectively than at longer wavelengths (i.e., Rayleigh scattering). As the concentrations of phytoplankton and suspended materials increase, absorption and scattering processes reduce the reflectance at blue wavelengths and increase the reflectance at green wavelengths such that the color shifts from blue to green to brown. This spectral shift in reflectance with changing concentrations of optically active water column constituents can be quantified and used to estimate their concentrations [Kirk, 2011].

The goal of satellite ocean color analysis is to accurately estimate the water-leaving radiance spectra in order to derive other geophysical and optical quantities from those spectra, e.g. the concentration of the photosynthetic pigment chlorophyll-a and metrics for light penetration. The motivation for spaceborne observations of this kind lies in the need for frequent highresolution measurements of these geophysical parameters on regional and global scales for addressing both research and operational requirements associated with marine primary production, ecosystem dynamics, fisheries management, ocean dynamics, water quality, and 
coastal sedimentation and pollution, to name a few [McClain, 2009]. The first proof-of-concept satellite ocean color mission was the Coastal Zone Color Scanner (CZCS, US, 1978-1986) on the Nimbus-7 spacecraft, which was launched in the summer of 1978. The CZCS was intended to be a one year demonstration with very limited data collection, ground processing, and data validation requirements. However, because of the extraordinary quality and unexpected utility of the data for both coastal and open ocean research, data collection continued until July 1986 when the sensor ceased operating. The entire CZCS data set was processed, archived, and released to the research community by 1990 [Feldman et al., 1989]. As a result of the CZCS experience, a number of other ocean color missions have been launched, e.g., the Ocean Color and Temperature Sensor (OCTS, Japan, 1996-97), the Sea-viewing Wide Field-of-view Sensor (SeaWiFS, US, 1997-2010), the Moderate Resolution Imaging Spectroradiometer (MODIS, US, 2000 and continuing), the Medium Resolution Imaging Spectrometer (MERIS, Europe, 20022012), and the Visible Infrared Imaging Radiometer Suite (VIIRS, US, 2012 and continuing), with the expectation that continuous global observations will be maintained as part of an operational monitoring program (Table 1).

\begin{tabular}{|c|c|c|c|c|c|c|}
\hline Mission & Agency & Sensor & Launch & Bands* & Resolution (m) & Other Specifications \\
\hline \multicolumn{7}{|c|}{ High spatial resolution missions ( 100 km swath) } \\
\hline Landsat-8, -9 & USGS/NASA & OLI, OLI-II & 2013,2020 & $4 \mathrm{VIS}$ & 30 & 16-day revisit \\
\hline Sentinel 2A, 2B & ESA & MSI & 2015,2017 & $4 \mathrm{VIS}$ & 10 & $\begin{array}{l}\text { 10-day revisit } \\
5 \text {-day in constellation }\end{array}$ \\
\hline EnMAP & DLR & EnMAP & 2017 & UV-SWIR $\left(6.5 \mathrm{~nm}^{+}\right)$ & 30 & 4-day revisit \\
\hline \multicolumn{7}{|c|}{ Geostationary missions } \\
\hline Geo-Kompsat 2B & KIOST & GOCl-II & 2019 & $1 \mathrm{UV}, 8 \mathrm{VIS}$ & $\begin{array}{l}250 \text { local } \\
1000 \text { global }\end{array}$ & $\begin{array}{l}\text { Geostationary } \\
\text { over NE Asia }\end{array}$ \\
\hline \multicolumn{7}{|c|}{ Medium spatial resolution missions ( 1000 km swath) } \\
\hline Nimbus-7 & NASA & CZCS & $1978-1986$ & $5 \mathrm{VIS}$ & 1000 & Regional coverage \\
\hline ADEOS & NASDA & OCTS & 1996-1997 & $8 \mathrm{VIS}$ & 1000 & 3-day global \\
\hline Orbview-2 & NASA/Orbital & SeaWiFS & $1997-2010$ & $8 \mathrm{VIS}$ & 1000 & 2-day global \\
\hline Terra, Aqua & NASA & MODIS & 1999-, 2002-present & 9 VIS & 1000 & 2-day global \\
\hline Envisat & ESA & MERIS & 2002-2012 & $8 \mathrm{VIS}$ & $\begin{array}{l}350 \text { local } \\
1000 \text { global }\end{array}$ & $\begin{array}{l}\text { 3-day global } \\
15 \text { total tunable bands }\end{array}$ \\
\hline Suomi NPP, JPSS-1 & NOAA/NASA & VIIRS & 2012-,2017-present & $5 \mathrm{VIS}$ & 750 global & 2-day global \\
\hline Sentinel 3A, 3B & ESA & $\mathrm{OLCl}$ & 2016, 2018 & $8 \mathrm{VIS}$ & $\begin{array}{l}300 \text { coastal } \\
1000 \text { ocean }\end{array}$ & $\begin{array}{l}\text { 4-day global } \\
\text { 2-day in constellation }\end{array}$ \\
\hline Oceansat-3 & ISRO & OCM-3 & 2018 & $8 \mathrm{VIS}$ & 360 & 2-day global \\
\hline GCOM-C & JAXA & SGLI & 2018 & $1 \mathrm{UV}, 6 \mathrm{VIS}$ & $\begin{array}{l}250 \text { coastal } \\
1000 \text { ocean }\end{array}$ & $\begin{array}{l}\text { 2-day global } \\
2 \text { polarized bands }\end{array}$ \\
\hline PACE & NASA & $\mathrm{OCl}$ & 2022 & UV-SWIR $\left(5 \mathrm{~nm}^{+}\right)$ & 1000 & 2-day global \\
\hline
\end{tabular}

* UV = ultraviolet $(350-400 \mathrm{~nm}), \mathrm{VIS}=$ visible $(400-900 \mathrm{~nm})$, SWIR = shortwave infrared $(900-2300 \mathrm{~nm})$; only ocean color bands considered + Indicates continuous resolution from UV-VIS at the wavelength step listed

Due to the multiplicity of international ocean biology missions, efforts to coordinate activities such as science data product algorithms, atmospheric correction algorithms, sensor calibration methodologies, and product validation databases have been undertaken. One of the primary goals is to achieve consistency in data quality and products between and across missions. Two such programs are the Sensor Intercomparison and Merger for Biological and Interdisciplinary Oceanic Studies (SIMBIOS, US, 1996-2003) and the International Ocean Colour Coordinating Group (IOCCG, 1996-present). Both activities have generated a number of technical reports that are available at https://oceancolor.gsfc.nasa.gov and 
Data Analysis System (SeaDAS), continues to provide NASA's standard ocean color data processing code at no cost, with a user-friendly menu-driven interface that allows users to tailor their analyses and studies. While originally developed for SeaWiFS, SeaDAS currently incorporates processing capabilities for a number of other US and international ocean color missions in collaboration with the international agencies. NASA also supports the Aerosol Robotic Network (AERONET), an international network of sites with standardized instrumentation, sensor calibration, data processing procedures, and data archival and distribution capabilities. These data are used in ocean color mission product validation.

\section{Ocean Color Theoretical and Observational Basis}

Reflectance can be defined in a number of ways. The most common definition for spectral irradiance reflectance, $R(\lambda)$ (unitless), just below the surface is:

where $E_{u}(\lambda)$ and $E_{d}(\lambda)$ are spectral upwelling and downwelling irradiances $\left(\mu \mathrm{W} \mathrm{cm} \mathrm{cm}^{-1}\right)$, respectively, and $0^{-}$implies a value just beneath the sea surface. In general, irradiance and radiance are functions of depth (or altitude in the atmosphere) and viewing geometry with respect to the Sun. $R(\lambda)$ has been theoretically related to the absorption and scattering properties of the ocean as:

where $f(\lambda)$ is a unitless function of solar geometry, sky conditions, and sea state, among other things, and is approximately equal to $0.33, b_{b}(\lambda)$ is the backscattering coefficient $\left(\mathrm{m}^{-1}\right)$, and $a(\lambda)$ is the absorption coefficient $\left(\mathrm{m}^{-1}\right)$. Eq. [2] holds where $b_{b}(\lambda)<<a(\lambda)$, which is the case for most coastal and open ocean waters. Both $b_{b}(\lambda)$ and $a(\lambda)$ represent the sum of the contributions of various optical components following:

$$
R(\lambda) \cong f(\lambda) \frac{b_{b}(\lambda)}{a(\lambda)+b_{b}(\lambda)}
$$

$$
b_{b}(\lambda)=b_{b w}(\lambda)+\sum_{i=0}^{N_{N A P}} b_{b, N A P, i}(\lambda)+\sum_{i=0}^{N_{p h}} b_{b, p h, i}(\lambda), \text { and }
$$

$$
a(\lambda)=a_{w}(\lambda)+\sum_{i=0}^{N_{N A P}} a_{N A P, i}(\lambda)+\sum_{i=0}^{N_{p h}} a_{p h, i}(\lambda)+\sum_{i=0}^{N_{C D O M}} a_{C D O M, i}(\lambda),
$$

where the subscripts $w, N A P, p h$, and $C D O M$ refer to contributions by water, non-algal particles (NAP), phytoplankton, and colored dissolved organic matter (CDOM), respectively. $N$ indicates the number of additional subcomponents in each category (i.e., $N_{p h}=3$ indicates three phytoplankton groups). Both $b_{b}(\lambda)$ and $a(\lambda)$ can be further expressed as the product of a component concentration $\left(\mathrm{mg} \mathrm{m}^{-3}\right)$ and its component-specific spectral shape $\left(\mathrm{m}^{2} \mathrm{mg}^{-1}\right)$. In the case of phytoplankton absorption, for example, this can be expressed as: 
where [Chla] indicates the concentration of the photosynthetic pigment chlorophyll- $a$ and $a^{*}{ }_{p h}(\lambda)$ indicates its chlorophyll-specific absorption spectrum. Absorption coefficients are designated for phytoplankton rather than chlorophyll- $a$ because the actual absorption by living cells can vary substantially for a fixed amount of chlorophyll-a.

The relationship between the upwelling radiance, $L_{u}(\lambda)\left(\mu \mathrm{W} \mathrm{cm}-2 \mathrm{~nm}^{-1} \mathrm{sr}^{-1}\right)$, and $E_{u}(\lambda)$ follows:

$$
L_{u}(\lambda)=\frac{E_{u}\left(\lambda, 0^{-}\right)}{Q(\lambda)}
$$

If the angular distribution of $E_{u}(\lambda)$ were directionally uniform - that is, Lambertian $-Q(\lambda)$ would equal $\pi$ across the spectrum. However, the irradiance distribution is not uniform and is dependent on a number of variables. Experimental results indicate that $Q(\lambda)$ is roughly 4.5.

For satellite applications, it is more appropriate to use the reflectance just above the surface than $R(\lambda)$. Therefore, remote sensing reflectance, $R_{r s}(\lambda)\left(\mathrm{sr}^{-1}\right)$ and normalized water-leaving

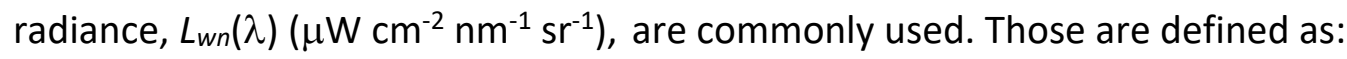

$$
R_{r s}(\lambda)=\frac{L_{w}(\lambda)}{E_{d}\left(\lambda, 0^{+}\right)}, \text {and }
$$

$$
L_{w n}(\lambda)=\left(\frac{1-\rho(\lambda)}{n^{2}(\lambda)}\right) \frac{L_{u}\left(\lambda, 0^{-}\right) F_{0}(\lambda)}{E_{d}\left(\lambda, 0^{+}\right)}
$$

where $\rho(\lambda)$ is the surface Fresnel reflectance (unitless), $n(\lambda)$ is the index of refraction of seawater (unitless), $F_{0}(\lambda)$ is the extraterrestrial solar irradiance $\left(\mu \mathrm{W} \mathrm{cm} \mathrm{cm}^{-1}\right), L_{w}(\lambda)$ is the

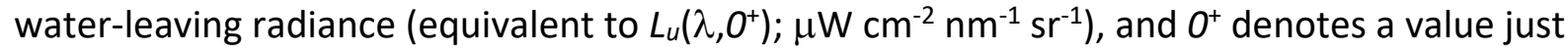
above the air-sea interface. The water-leaving radiance is the upwelled radiance just above the surface, excluding the light reflected by the surface. The term in parenthesis is approximately 0.54 , indicating that water-leaving radiance is proportional to subsurface upwelled radiance:

$$
L_{w}(\lambda) \approx 0.54 L_{u}\left(\lambda, 0^{-}\right)
$$

Thus, $\underline{R}_{r s}(\lambda)$ is proportional to $L_{w n}(\lambda)$ through $F_{0}(\lambda)$. Surface reflectance includes the direct component of photons not scattered by the atmosphere, the indirect component from photons that are scattered by the atmosphere (skylight), and the contribution of whitecaps. The angular distribution of surface reflection broadens as wind speed increases and the sea surface roughens. The contributions from whitecaps also increases with wind speed. 
Other optical parameters of interest include diffuse attenuation coefficients for upwelling radiance, $K_{L u}(\lambda, z)\left(\mathrm{m}^{-1}\right)$, and downwelling irradiance $K_{d}(\lambda, z)\left(\mathrm{m}^{-1}\right)$, both of which provide indicators of light penetration (and, thus, water quality):

$$
K_{L u}(\lambda, z)=\frac{1}{L_{u}(\lambda, z)} \frac{\mathrm{d} L_{u}(\lambda, z)}{\mathrm{d} z}, \text { and }
$$

Near the surface where optical constituents are relatively uniform - thus, diffuse attenuation coefficients vary little with depth $-L_{u}(\lambda, z)$ and $E_{d}(\lambda, z)$ can be described as:

$$
L_{u}(\lambda, z)=L_{u}\left(\lambda, 0^{-}\right) \exp ^{-K_{L u}(\lambda) z}, \text { and }
$$

$$
E_{d}(\lambda, z)=E_{d}\left(\lambda, 0^{-}\right) \exp ^{-K_{d}(\lambda) z}
$$

The upwelling and downwelling diffuse attenuation coefficients for radiance and irradiance are commonly interchanged, but strictly speaking, they are different quantities and are not equal.

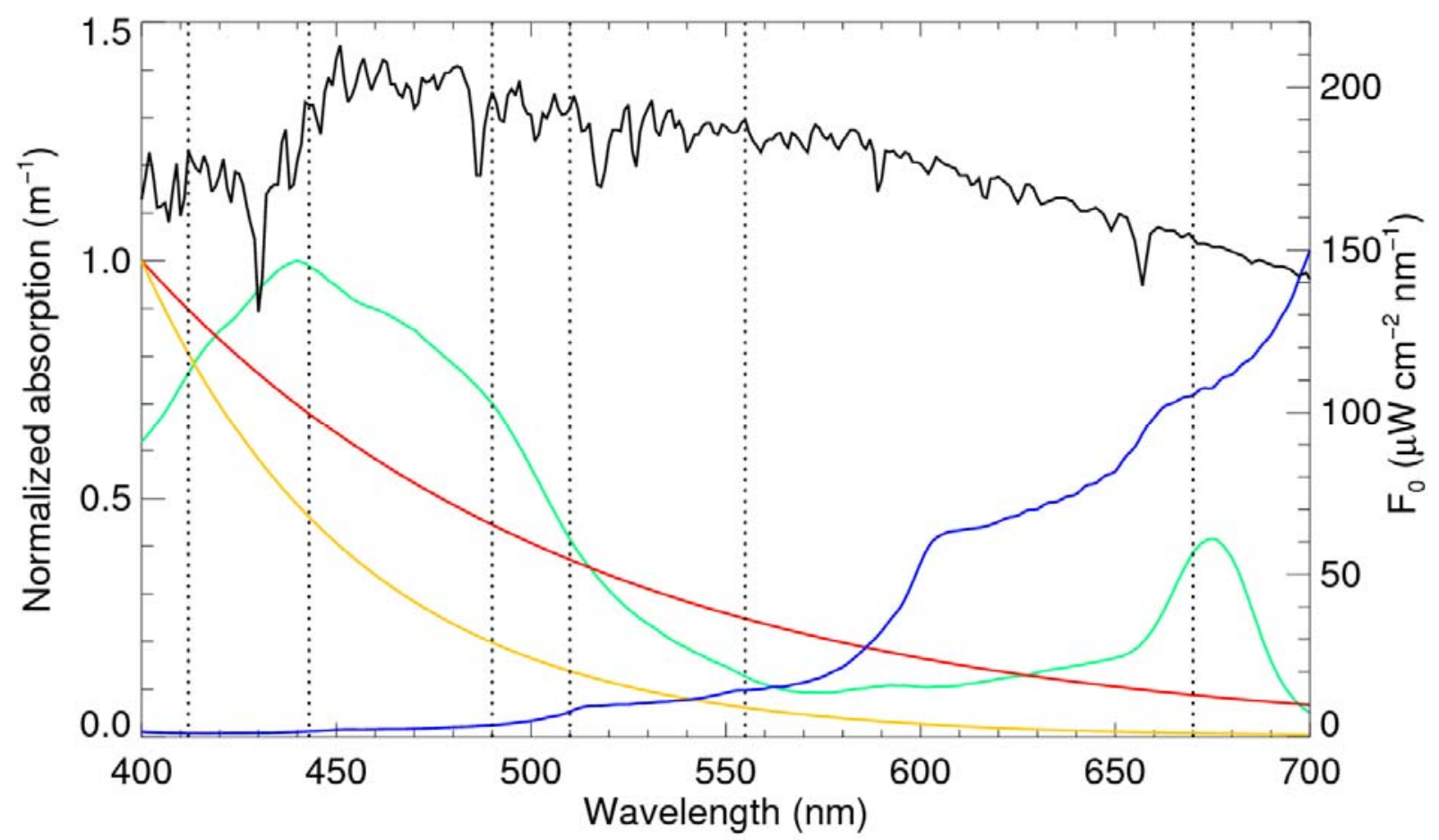

Figure 1. Normalized absorption spectra for phytoplankton (green), seawater (blue), NAP (red), and CDOM (yellow) (left axis), plus solar irradiance (black) (right axis). Dashed lines indicate SeaWiFS wavelengths.

Key to ocean biology long-term climate data records are the relationships between the solar irradiance, water absorption, and chlorophyll- $a$ absorption spectra, with chlorophyll- $a$ being the primary chemical associated with photosynthesis. The solar spectrum peaks at blue 
wavelengths that correspond to the maximum transparency of water and the peak in chlorophyll- $a$ absorption. Thus, phytoplankton photosynthesis is tuned to the spectral range of maximum light. Figure 1 provides spectra for $F_{0}(\lambda), a^{*}{ }_{p h}(\lambda), a_{w}(\lambda)$, and others. Note that heritage multispectral satellite instrument wavelength suites were specifically selected to exploit differences in the optical signatures of these components. Both Mobley [1994] and Kirk [2011] provide useful resources for exploring ocean color theoretical bases further.

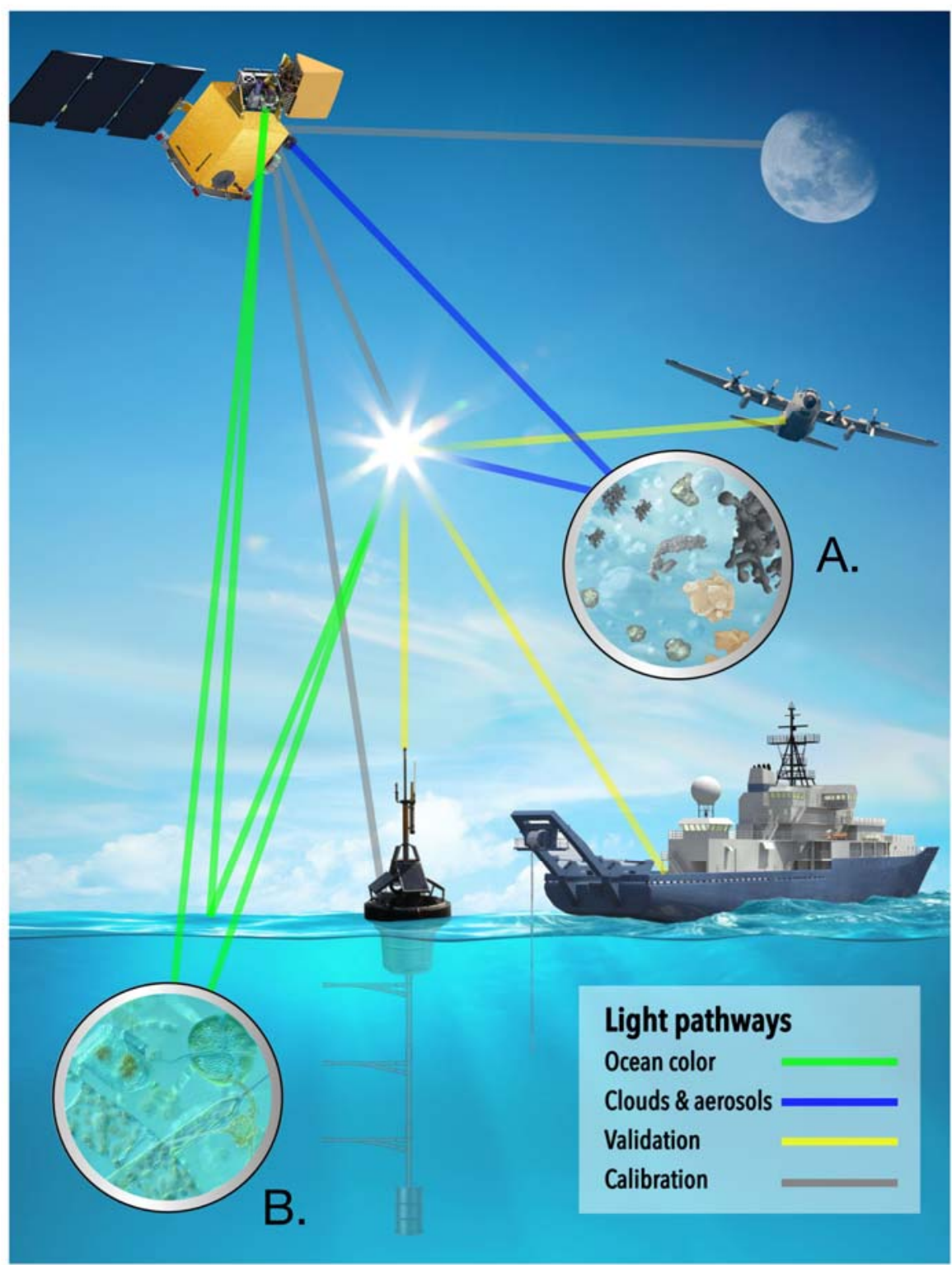

Figure 2. Depiction of various sensor, atmospheric, and oceanic optical pathways relevant to satellite ocean color data processing. Addressing the atmosphere (circle $A$ ) requires accounting for air molecules, airborne particles, and absorbing gases (e.g., $\mathrm{O}_{2}, \mathrm{O}_{3}, \mathrm{H}_{2} \mathrm{O}, \mathrm{NO}_{2}$, and $\mathrm{CO}_{2}$ ). Addressing the ocean (circle $\mathrm{B}$ ) requires accounting for water molecules, algal particles, non-algal particles, and optically active dissolved material. The Sun, Moon, and at-sea measurements are all used for satellite ocean color instrument calibration. At-sea and aircraft measurements are all used for satellite ocean color data product validation. 


\section{Satellite Ocean Color Methodology}

In order to obtain accurate estimates of geophysical quantities, such as [Chla] and $K_{d}(\lambda)$, from satellite measurements, a number of radiometric issues must be addressed including: (1) sensor design and performance; (2) post-launch sensor 'vicarious' calibration (the absolute adjustment of prelaunch spectral gain factors) and calibration stability (the time-dependent adjustment for sensor loss of spectral sensitivity); (3) atmospheric correction, that is, the removal of light due to atmospheric scattering, atmospheric absorption, and surface reflection; and, (4) bio-optical algorithms, that is, the transformation of $R_{r s}(\lambda)$ values into geophysical parameter values. Items (2)-(4) represent developments that progress over time during a mission. Also, as radiative transfer theory develops and additional optical data are obtained, atmospheric correction and bio-optical algorithms improve and replace previous versions and new data products are defined by the research community. Therefore, flight projects are prepared to periodically satellite measurement scenario, each aspect of which is discussed below.

\section{Sensor Design and Performance}

Sensor design and performance characteristics encompass many considerations that cannot be elaborated on here, but are essential to meeting the overall measurement accuracy requirements [Donlon et al., 2014]. Radiometric factors include wavelength selection, spectral bandwidth, saturation radiances, signal-to-noise ratios, polarization sensitivity, temperature sensitivity, scan angle dependences (scan modulation), stray-light rejection, out-of-band contamination, field-of-view (spatial resolution), band co-registration, and a number of others, all of which must be accurately quantified (characterized) prior to launch and incorporated in the data processing algorithms. Usually, ocean color sensors also incorporate a depolarizer to minimize polarization sensitivity because the Rayleigh radiance from the atmosphere is highly polarized. Other design features may include a sensor that tilts fore and aft to avoid Sun glint and capacities for tracking the sensor stability on-orbit (e.g., internal lamps, solar diffusers and lunar views), as instruments generally lose sensitivity over time due to contamination of optical components and spectral filter degradation, to name only a few. A variety of spacecraft design criteria also exist, including attitude control for accurate navigation, power (solar panel and battery capacities), onboard data storage capacity, telemetry bandwidth (command uplink and downlink data volumes, transmission frequencies, and ground station compatibility and contact constraints), and real-time data broadcast and ground station compatibility. Depending on the specifications, ocean color instruments can be built in a variety of ways to optimize performance [IOCCG, 2012]. Designs generally fall into two categories, pushbroom and whiskbroom. Pushbroom sensors incorporate a camera system which illuminates a 2-D detector array providing both spectral and spatial cross-satellite track sampling). The array is read-out and resampled at the frequency required to yield continuous along-track coverage. A whiskbroom sensor incorporates a scanning mechanism so that the scan rate is synchronized to 
the ground track velocity to yield continuous spatial coverage. A whiskbroom sensor has detector(s) only for spectral sampling as the same detectors are used for each ground sample or pixel. MERIS was a pushbroom sensor with seven separate cameras to achieve a wide crosstrack sampling or swath. The CZCS, SeaWiFS and MODIS were whiskbroom designs. Spectral sampling is achieved using gratings, prisms, or absorption filters. For example, the CZCS and MERIS used gratings for spectral separation while SeaWiFS and MODIS used filters.

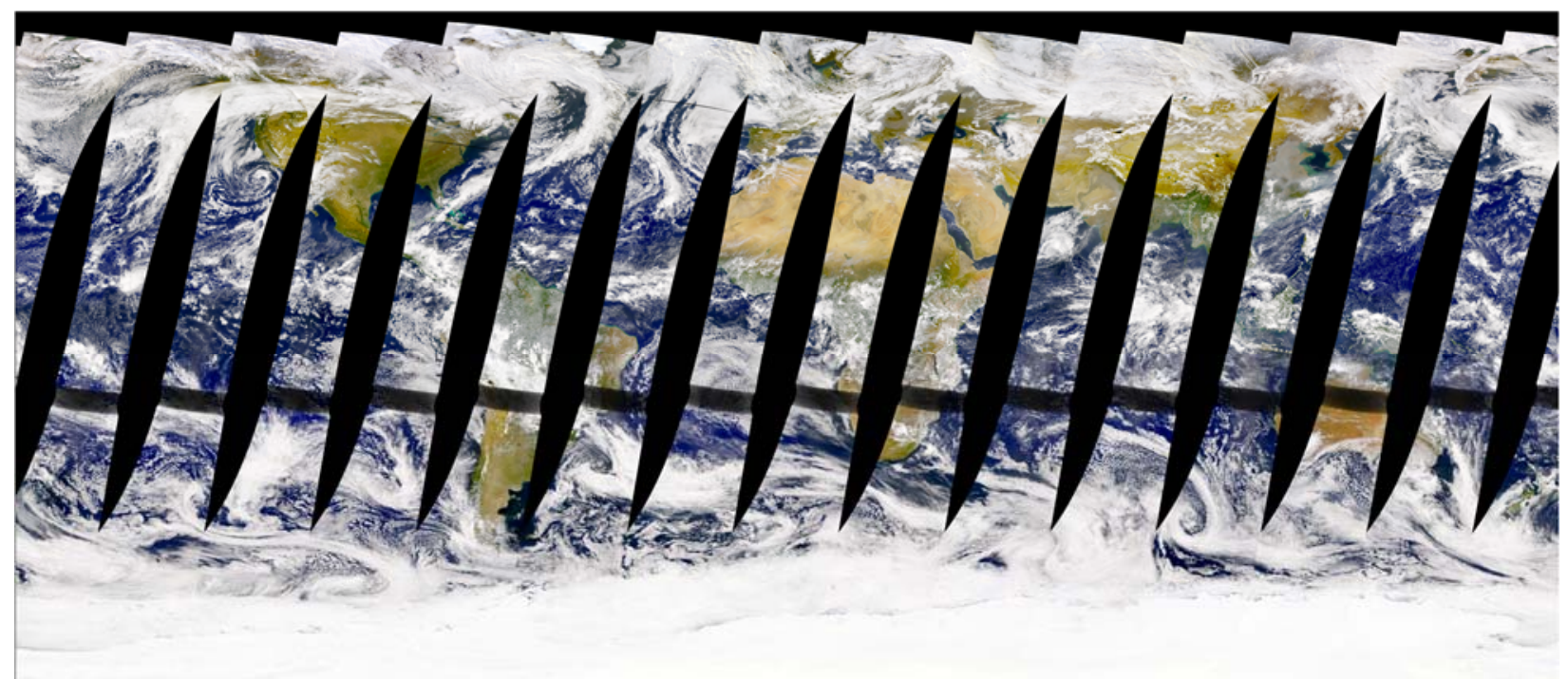

Figure 3. An example of daily global coverage from SeaWiFS.

Nearly all ocean color missions to date, both previous and currently approved, have been designed for low-altitude sun-synchronous orbits, although sensors on high-altitude geostationary platforms exist (Table 1) [Martin, 2014; Robinson, 2004]. Sun-synchronous orbits, generally called low-Earth orbits (LEO) provide global coverage as the Earth rotates under the fixed satellite orbit so the data are collected at the same local time every day. Multiple views for a given day are possible only at high latitudes where the orbit tracks converge. Typically, ocean color missions fly at an altitude of $650-800 \mathrm{~km}$. Figure 3 shows the daily coverage of SeaWiFS. The gaps between the swaths are filled on the following day as the ground track pattern progressively shifts, resulting in 2-day global coverage. The data gaps in each swath about the subsolar point are where the sensor is tilted from $-20^{\circ}$ to $+20^{\circ}$ to avoid viewing into Sun glint (a feature of only CZCS, OCTS, SeaWiFS, and PACE inclusive of those missions listed in Table 1). The tilt operation was staggered on successive days in order to ensure every-other-day coverage of the gap. Geostationary orbits (GEO), that is, orbits having a fixed subsatellite (nadir) point on the equator, only allow hemispheric coverage with decreased spatial resolution away from nadir but can provide multiple views each day. Multiple views per day allow for the evaluation of tidal and other diurnal time dependent biases in sampling to be evaluated, and also provide more complete sampling of a given location as cloud patterns change. GEO orbits are at $\sim 38,800 \mathrm{~km}$. All design types and orbit categories have distinct advantages and challenges, e.g., trades between signal-to-noise and ground sampling and on- 


\section{Post-launch Sensor Calibration Stability}

The sensitivity of any satellite sensor will drift over time, usually becoming less sensitive. The causes can be from any number of effects, such as outgassed organics collecting on the optical surfaces and radiation degradation of the detectors. Without correction, the data become unusable for scientific research and, therefore, methodologies for tracking sensor sensitivity or calibration must be incorporated into the sensor and mission design [Eplee et al., 2013]. For instance, the CZCS sensitivity at $443 \mathrm{~nm}$ changed by $~ 50 \%$ during its 7.7 years of operation and SeaWiFS sensitivity at $865 \mathrm{~nm}$ degraded by as much as $20 \%$, with very little loss of sensitivity at $443 \mathrm{~nm}$, during its 13 years of operations. Quantifying changes in the sensor can be very difficult, especially if the changes are gradual. In the case of the CZCS, there was no on-going comprehensive validation program after its first year of operation, because the mission was a proof-of-concept. As a result, subsequent missions have some level of continuous validation. In the case of SeaWiFS, a combination of solar, lunar, and field observations (oceanic and atmospheric) were used (Figure 2). The solar measurements were made daily using a solar diffuser to detect sudden changes in the sensor (none occurred). The solar measurements cannot be used as an absolute calibration because the diffuser reflectance gradually changes over time unless the sensor has a separate system to track the reflectance of the diffuser (MODIS, e.g., incorporated a diffuser stability monitor). SeaWiFS was the first mission to make monthly lunar measurements at a fixed lunar phase angle (7 degrees), which provided an accurate estimate of the sensor stability relative to the first lunar measurement. The lunar measurements cannot be used for an absolute calibration because the Moon's surface reflectance is not known to a sufficient accuracy. As a result of the success of SeaWiFS, lunar measurements have become a standard approach adopted by other missions and space agencies. Contamination of optical surfaces can also change other radiometric characteristics, such as polarization sensitivity, as happened with MODIS on Terra. Neither MODIS instrument incorporated a depolarizer because of other design requirements. However, during the period of overlap with SeaWiFS, SeaWiFS data was used to characterize the time-dependent change in MODIS-Terra polarization sensitivity [Meister et al., 2012].

Another calibration correction, the 'vicarious' calibration, is generally applied once a mission is on orbit [Franz et al., 2007]. This on-orbit adjustment tunes each sensors' wavelength calibrations to ground observations and simultaneously accounts for changes in the prelaunch calibration and any biases in the atmospheric correction scheme. A vicarious calibration correction requires time-series of spectral water-leaving radiances from uniform, clear-water regions where geophysical variability is relatively small or very well understood. The Marine Optical Buoy (MOBY, US, 1996-present) located off Lanai, Hawaii provides an example of one such system [Clark et al., 1997]. MOBY provides high resolution visible spectral data that can be tailored to match the spectral bands of every ocean color mission flown since 1996. The vicarious technique compares simultaneous measurements from MOBY and the satellite sensor of interest. Typically, thirty or more such match-ups are needed to achieve an accurate estimate of the adjustment factors. In-water measurements, however, cannot assess biases in near-infrared band calibrations. Atmospheric measurements of optical depths and other 
parameters, usually at sites in the mid-ocean gyres where marine aerosols are dominant, are used for corrections at these wavelengths.

\section{Atmospheric Correction}

Deriving water-leaving radiances or reflectances requires estimation (and removal) of atmospheric contributions from the total signal measured by the satellite instrument [Mobley et al., 2016]. Solar irradiance propagates through the atmosphere, where it is attenuated by molecular (Rayleigh) and aerosol scattering and absorption. Rayleigh scattering can be calculated theoretically with a high degree of accuracy. Aerosol scattering and absorption are much more difficult to estimate because their horizontal and vertical distributions are highly variable, as are their absorption and scattering properties. The estimation of the aerosol effects on the upwelling radiance at the top of the atmosphere is one of the most difficult aspects of satellite remote sensing. Ozone is the primary absorbing gas that must be considered. Fortunately, ozone is concentrated in a thin band near the top of the atmosphere and its global distribution is mapped daily by other satellite sensors. Continuous global satellite ozone measurements have been made since 1978. Other absorbing gases that require corrections include $\mathrm{NO}_{2}$ and $\mathrm{O}_{2} . \mathrm{O}_{2}$ has a strong absorption band (A-band) between 750 and $770 \mathrm{~nm}$.

Light that reaches the surface is either reflected or penetrates through the air-sea interface. Simple reflection at a flat interface is called Fresnel reflection and is easily computed theoretically. However, if the surface is wind-roughened or includes foam (whitecaps), then the estimation of the reflected light is more complex and empirical relationships must be invoked. Only a small percentage of the light that enters the water column is reflected upward through the air-sea interface in the general direction of the satellite sensor. Of that light, only a fraction makes its way back through the atmosphere into the sensor. Each process must be accounted for in estimating the water-leaving radiances. The radiances associated with each process are additive, to the first order, and can be expressed as:

$$
L_{t}(\lambda)=L_{r}(\lambda)+\left[L_{a}(\lambda)+L_{r a}(\lambda)\right]+T(\lambda) L_{g}(\lambda)+t(\lambda) L_{f}(\lambda)+t(\lambda) L_{w}(\lambda)
$$

where the subscripts $r, a, r a, g$, and $f$ denote contributions from Rayleigh, aerosol, Rayleighaerosol interaction, Sun glint, and foam (white caps), respectively. $T(\lambda)$ is the direct transmittance (unitless) and $t(\lambda)$ is the diffuse transmittance (unitless). $L_{t}(\lambda)$ is the total radiance observed by the spaceborne sensor and depends only on the sensor calibration. $L_{r}(\lambda)$, $L_{g}(\lambda), L_{f}(\lambda), T(\lambda)$, and $t(\lambda)$ can be effectively calculated or modeled. The aerosol radiances (in 340 brackets) are usually inferred from near-infrared wavelengths, where $L_{w}(\lambda)$ is assumed to be negligible or effectively modeled. Determining values for all terms on the right side of Eq. [12], with the exception of $L_{w}(\lambda)$, constitutes the 'atmospheric correction,' which allows Eq. [12] to be solved for $L_{w}(\lambda)$. As mentioned earlier, if $L_{w}(\lambda)$ is known, then $L_{t}(\lambda)$, can be predicted - then, adjusted - to balance Eq. [12] to derive a 'vicarious' calibration of the visible bands. 


\section{Bio-optical Algorithms}

Bio-optical algorithms are used to define relationships between the water-leaving radiances or reflectances and constituents in the water column. These can be strictly empirical (statistical regressions) [O'Reilly et al., 1998] or semi-analytical algorithms (SAAs) [Werdell et al., 2018], which are typically based on a combination of empiricism and simplifications to the radiative transfer equations. The empirical relationship used to derive [Chla] from SeaWiFS, for example, is expressed as a polynomial as follows:

$$
\log _{10}[\text { Chla }]=a_{0}+a_{1} X+a_{2} X^{2}+a_{3} X^{3}+a_{4} X^{4},
$$

where $a_{0 . .4}=[0.3272,-2.9940,2.7218,-1.2259,-0.5683]$ and

$$
X=\log _{10}\left(\frac{R_{r s}(443)>R_{r s}(490)>R_{r s}(510)}{R_{r s}(555)}\right) .
$$

In Eq. [14], the numerator is the greatest of the three remote-sensing reflectances (Figure 4).

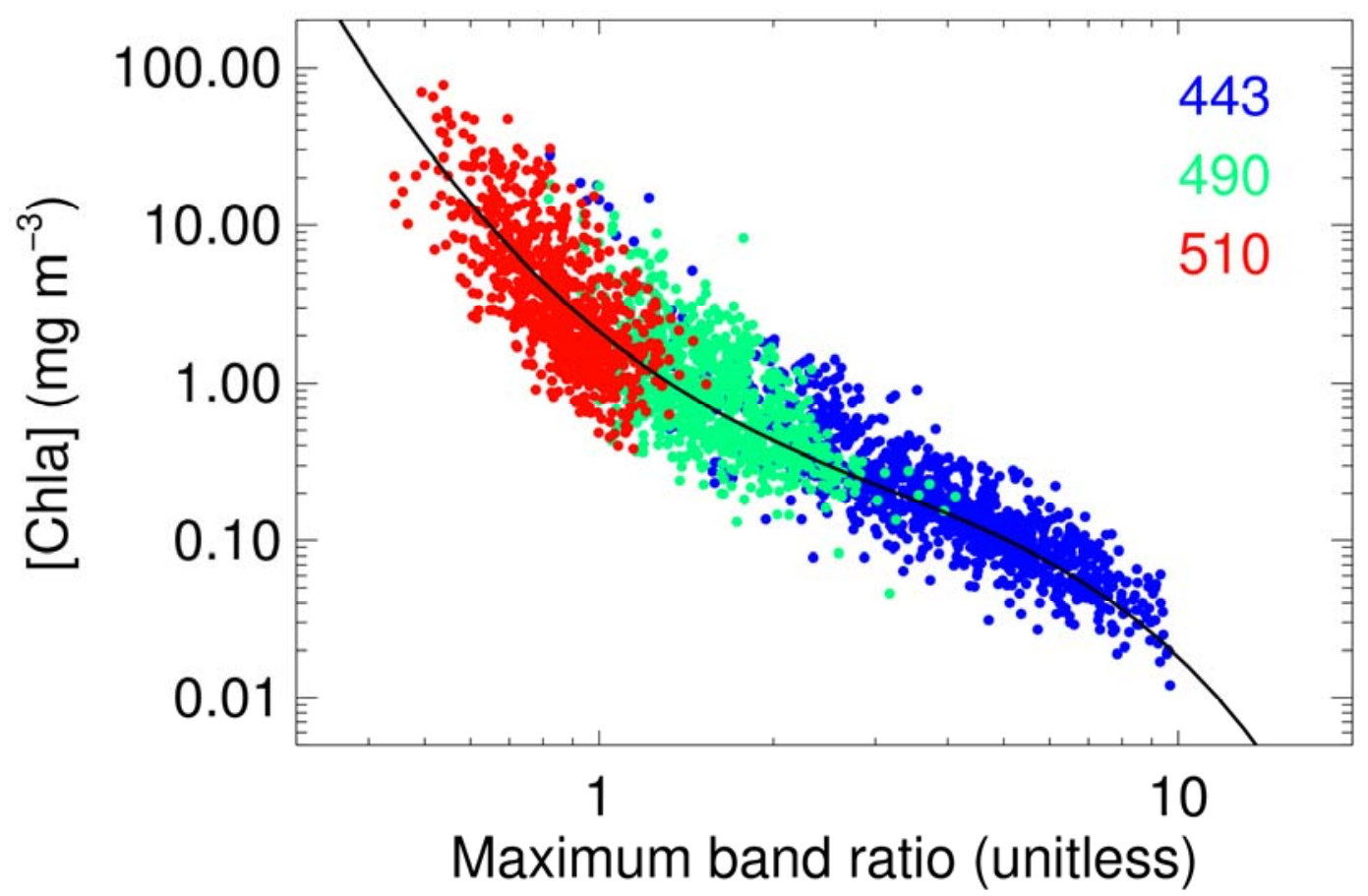

Figure 4. The 4-band Ocean Color Chlorophyll (OC4) algorithm for SeaWiFS. The solid black line shows the polynomial expression described by Eqs. [13-14]. The solid circles show the training data set, where blue, green, and red indicate where $\boldsymbol{R}_{r s}(443), \boldsymbol{R}_{r s}(490)$, and $\boldsymbol{R}_{r s}(510)$, respectively, are the greatest in Eq. [14].

Most SAAs attempt to simultaneously estimate the magnitudes of spectral backscattering by particles, absorption by phytoplankton, and the combined absorption by non-algal particles and colored dissolved organic material. This is typically accomplished by assigning constant spectral values for seawater absorption and backscattering, assuming spectral shape functions (eigenvectors) for the remaining constituent absorption and scattering components (e.g., Eq. 
[5]), and retrieving the magnitudes (eigenvalues) of each remaining constituent required to match the spectral distribution of remotely-sensed radiometric measurements (e.g., an inverse solution of Eqs. [2-4]). Such spectral-matching algorithms require contrasting optical signatures for the absorbing and scattering components within the spectral bands detected by the sensor.
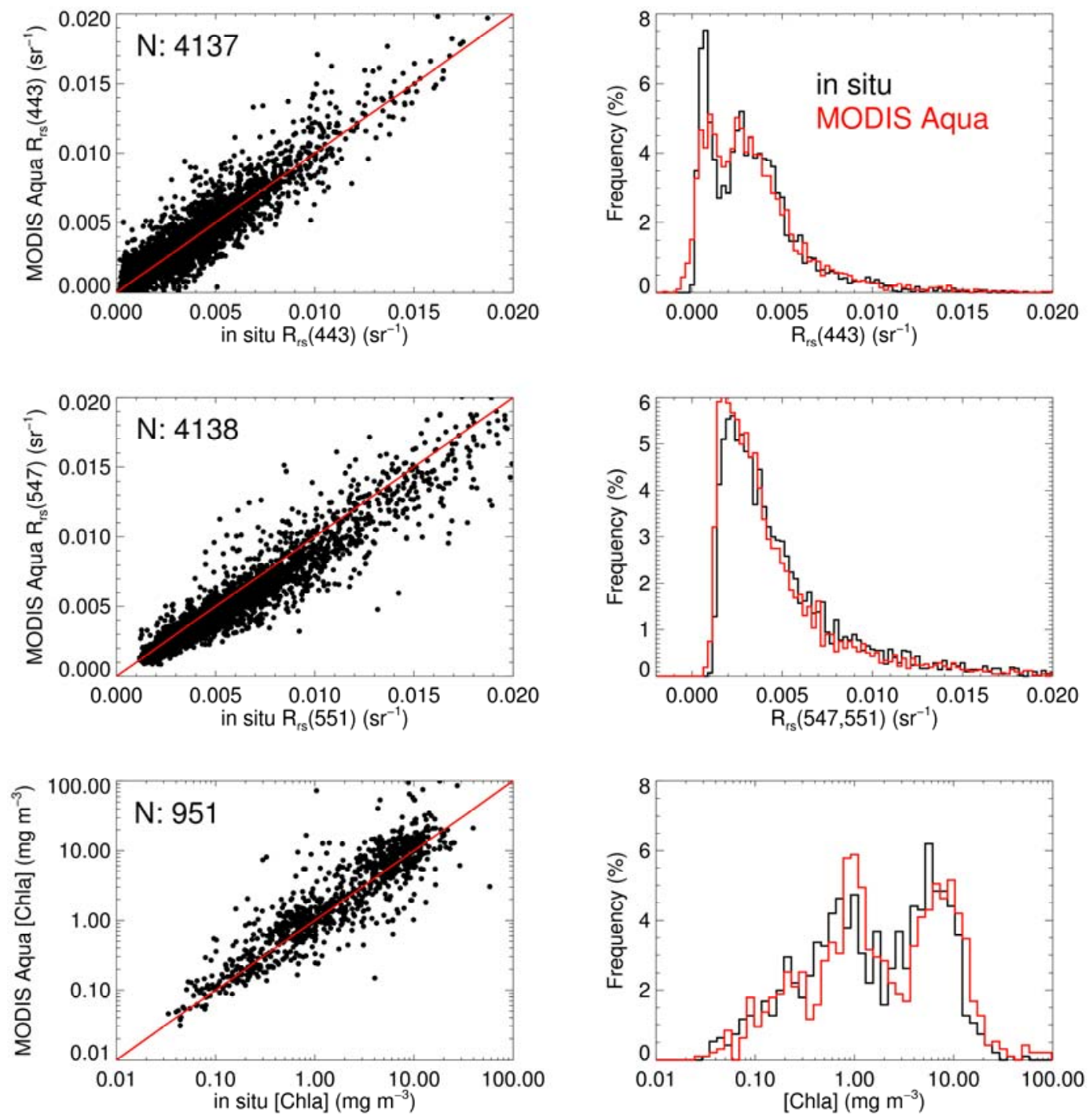

Figure 5. Satellite-to-in situ match-ups for MODIS-Aqua. Left column: Scatter plots where $\mathbf{N}$ is the sample size and the solid red lines shows a 1:1 relationship. Right column: Frequency histograms of the match-up pairs with in situ data shown in black and MODIS-Aqua data shown in red.

\section{Product Validation}

Satellite data product validation requires the accumulation of large volumes of high quality field data. Differences in field measurements and satellite estimates can be due to a number of sources, including erroneous satellite estimations of $L_{w}(\lambda)$, inaccurate in situ values, and biooptical algorithm error (e.g., error inherent to an empirical regression). To minimize in situ measurement errors, the SeaWiFS Project initiated a program to standardize the calibration of 
in situ radiometers, the development and documentation of in situ measurement protocols for all geophysical variables, the procedures used in data processing, and a bio-optical database for algorithm development and post-launch satellite derived product accuracy assessment (the SeaWiFS Bio-optical Archive and Storage System, SeaBASS). SeaBASS was augmented during the SIMBIOS Project to include the NASA bio-Optical Marine Algorithm Dataset (NOMAD), a highly quality assured data set for ocean color algorithm development. NASA continues to support SeaBASS and NOMAD as resources for the international community and similar international resources have more recently emerged.

Validation of derived geophysical products can be approached in several ways, most commonly using field (in situ) as ground-truth. The most straightforward approach involves comparison of simultaneously collected in situ and satellite data [Bailey and Werdell, 2006]. Such comparisons can provide accurate error estimates but, typically, only 5-10\% of the available in situ observations result in valid match-ups, mainly because of cloud cover and time-of-collection differences. Figure 5 shows coincident radiometric and [Chla] satellite-to-in situ match-ups for MODIS-Aqua, using AERONET and SeaBASS data, respectively. Another approach is the evaluation of population statistics with relaxed requirements on temporal coincidence, such as seasonal or basin-scale frequency distributions or monthly time-series of large in situ and satellite data sets [Werdell et al., 2009]. While statistical comparisons of such cumulative data sets allow utilization of far more data, they can still be subject to spatial or temporal sampling biases. An alternative approach that does not require in situ data is the comparison of measurements from different missions. Figure 6 shows mission-long monthly SeaWiFS and MODIS-Aqua time-series of [Chla] in deep water (> $1000 \mathrm{~m})$.

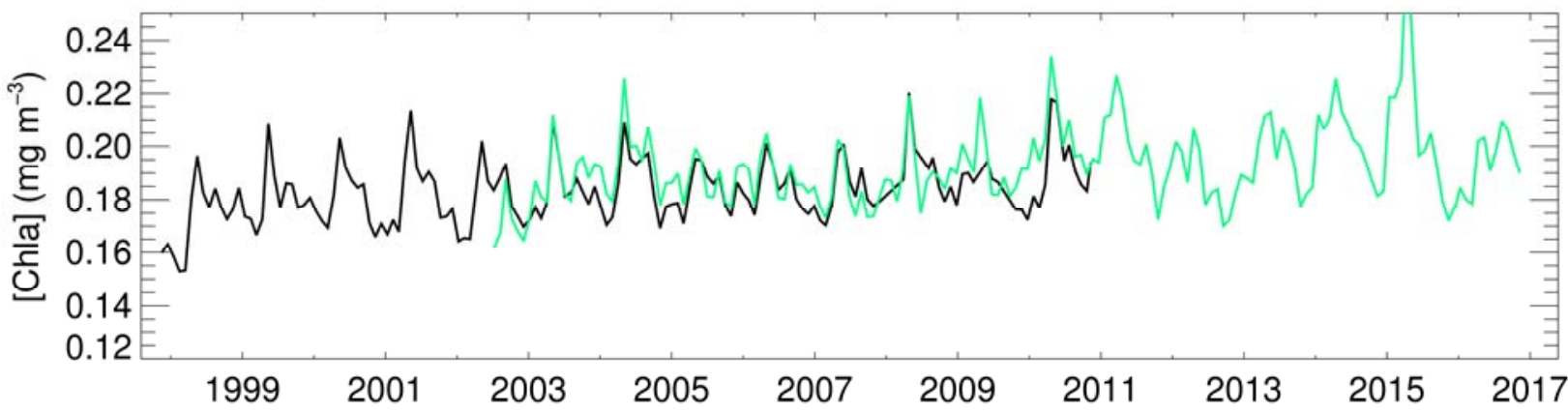
Figure 6. Example [Chla] monthly time-series from SeaWiFS (black) and MODIS-Aqua (green).

\section{Satellite Ocean Color Example Applications}

The number of derived data products from satellite ocean color instruments has increased substantially over the past four decades given improvements in computing power, better and more diverse field measurements, improved knowledge of ocean optics, unlimited access to the data records, and the varied instrument characteristics of the satellite missions (e.g., their spectral, spatial, and temporal resolutions). While originally conceived of to simply produce [Chla] imagery, satellite ocean color data sets now encompass fundamental marine optical properties, indices of water quality, and estimates of phytoplankton community structure and 
carbon stocks [IOCCG, 2008; 2009; 2014]. An exhaustive list of data products exceeds to scope of this chapter. Rather, this section highlights several spatial and temporal patterns that a satellite ocean color instrument can reveal, specifically evaluation of: (1) seasonal patterns on global scales; (2) inter-annual variability on basin-sized scales; and (3) regional patterns on short time scales.

431

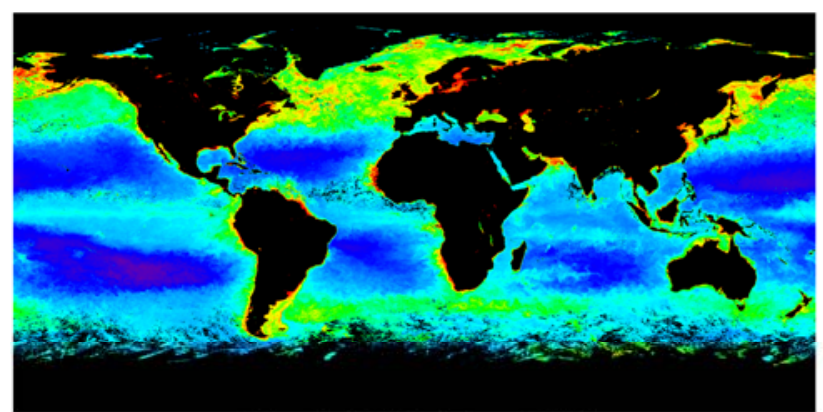

March 2017- May 2017

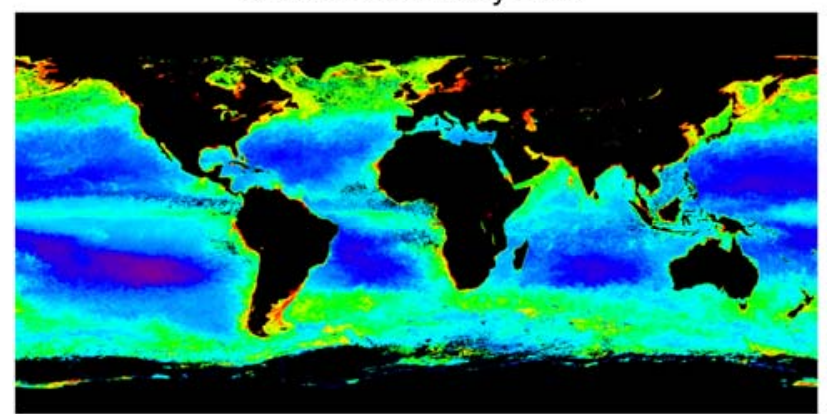

September 2017- November 2017

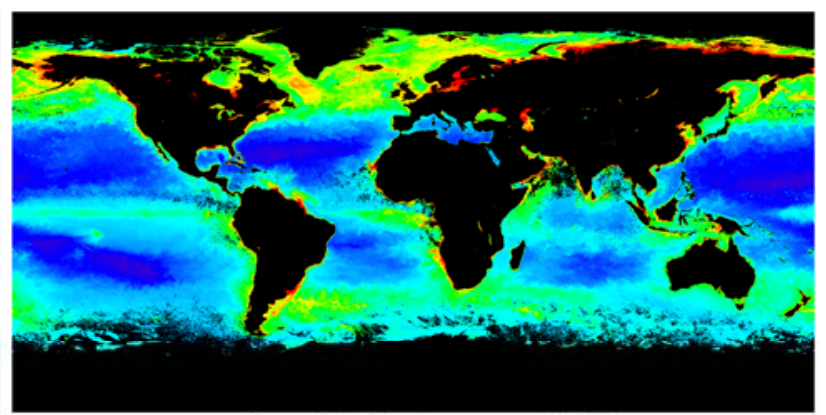

June 2017- August 2017

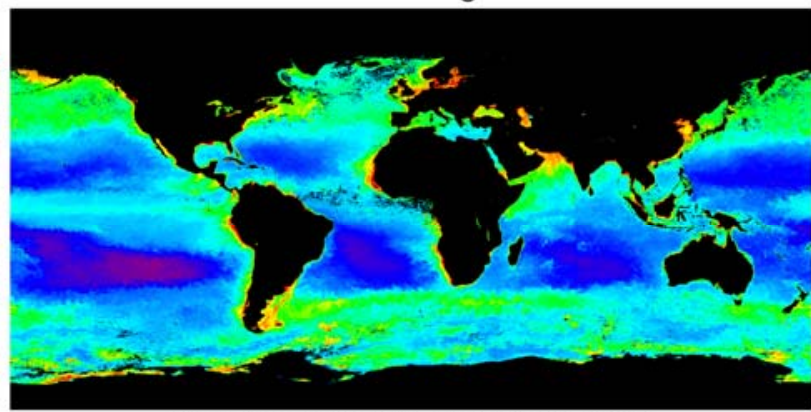

December 2017- February 2018
432

433

434

435

436

437

438

439

440

441

442

443

444

445

446

447

448

449

450

451

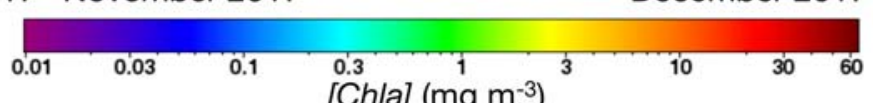

Figure 7. Seasonal average [Chla] from MODIS-Aqua. The composites combine all [Chla] retrievals within a 4km square 'bin' obtained during each 3-month period. A variety of quality control exclusion criteria are applied before a sample (pixel) is included in the average.

Plant growth in the ocean is regulated by the supply of macronutrients such as nitrate and silicate, micronutrients (iron in particular), light, and temperature. Light is modulated by cloud cover and time of year (through the solar zenith angle). Nutrient supply and temperature are determined by ocean circulation and mixing, especially the vertical fluxes, and heat exchange with the atmosphere. Figure 7 shows seasonal averages of [Chla] derived from MODIS-Aqua. Areas such as the North Atlantic show a clear seasonal cycle. The seasonality in the North Atlantic results from deep mixing of the water column in the winter, which renews the surface nutrient supply because the deeper waters are a reservoir for nitrate and other macronutrients. The traditional explanation is once illumination begins to increase in the spring, the depth to which mixing occurs shallows to provide a well-lit, nutrient-rich surface layer that is ideal for phytoplankton growth. A bloom results and persists into the summer until zooplankton grazing and nutrient depletion curtail the bloom.

Figure 8 depicts the effects of El Niño and La Niña on the ecosystems of the equatorial Pacific during 1997-98. Under normal conditions, the eastern equatorial Pacific is one of the most 
biologically productive regions in the world ocean, as westward winds force a divergent surface flow resulting in upwelling of nutrient-rich subsurface water into the euphotic zone, that is, the shallow illuminated layer where plant photosynthesis occurs. During El Niño, warm nutrientpoor water migrates eastward from the western Pacific and replaces the nutrient-rich water, resulting in a collapse of the ecosystem. Eventually, the ocean-atmosphere system swings back to cooler conditions, usually to colder than normal ocean temperatures, causing La Niña. The result is an extensive bloom that eventually declines to more typical concentrations as the atmosphere-ocean system returns to a more normal state.

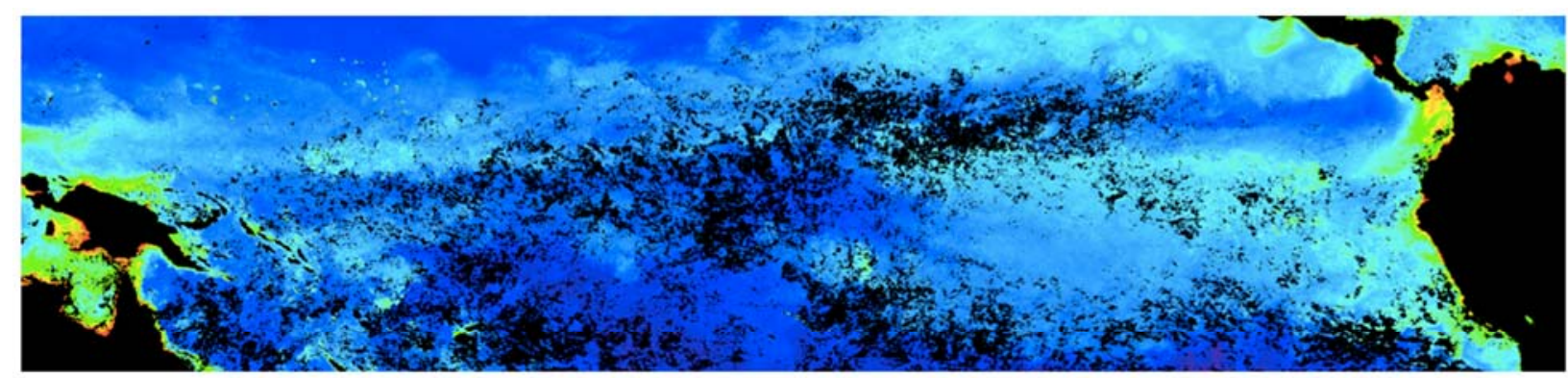

January 1998

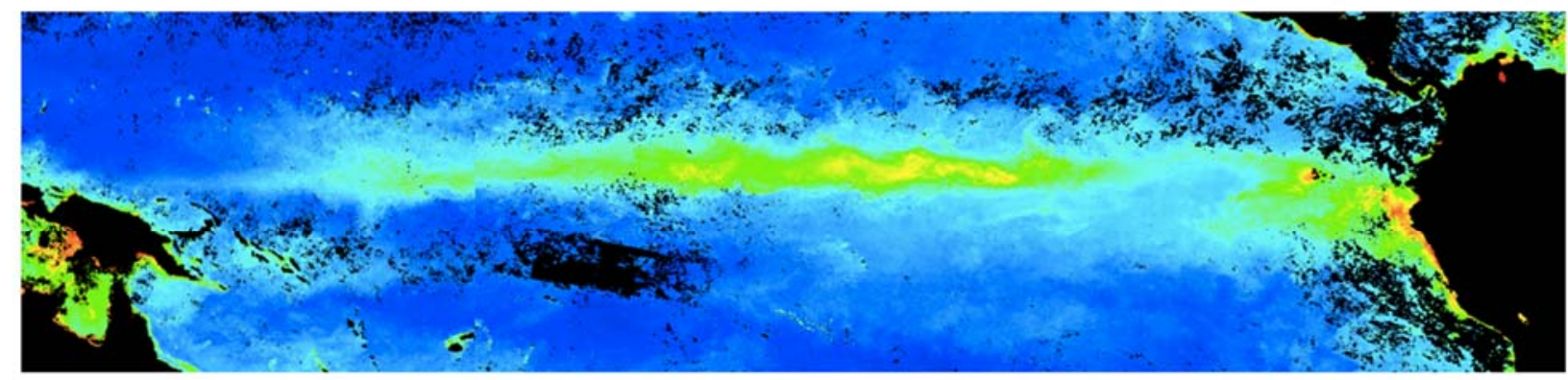

July 1998

461

462

463

464

465

466

467

468

469

470

471

472

473

474

475

476

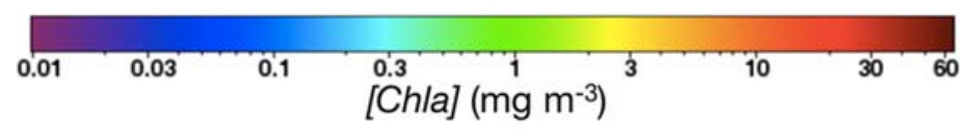

Figure 8. A comparison of the monthly average [Chla] at the peaks of the 1997 El Niño and the 1998 La Niña in the equatorial Pacific as observed by SeaWiFS.

The final example illustrates that some phytoplankton have special optical properties that allow them to be uniquely identified. Figure 9 shows extensive blooms of coccolithophores in the Bering Sea and of potentially toxic cyanobacteria in western Lake Erie. Coccolithophores shed carbonate platelets which turn the water a milky white in their mature stage of development and, under these conditions, the anomalously high reflectance allows for their unambiguous detection. Since coccolithophores are of interest for a number of ecological and biogeochemical purposes, satellite ocean color data can be used to map the temporal and spatial distribution of these blooms. In the case of the Bering Sea, the occurrence of coccolithophores had not been documented prior to 1997, when the bloom persisted for roughly 6 months. The ecological impact of the blooms in 1997 and 1998, which encompassed the entire western Alaska continental shelf, was dramatic and may have contributed to extensive starvation of marine mammals and seabirds and prevented salmon from spawning in the rivers along that coast. 


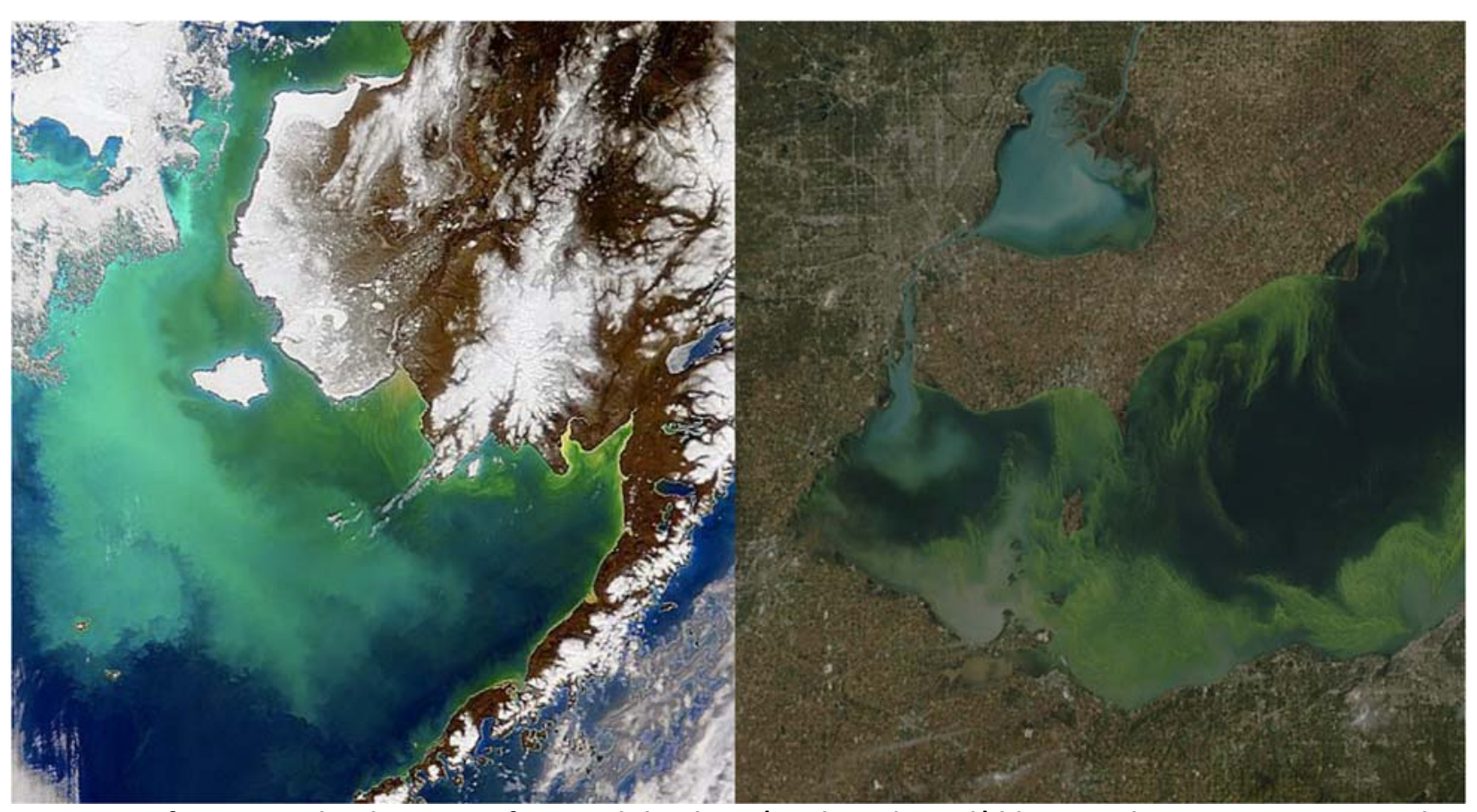

Figure 9. Left: A true color depiction of a coccolithophore (Emiliana huxeyli) bloom in the Bering Sea captured by SeaWiFS on 25 April 1998. Right: A true color depiction of a cyanobacteria bloom (mostly Microcystis aeruginosa) in western Lake Erie captured by MODIS-Aqua on 11 October 2011.

The green scum shown in the right side of Figure 9 represents one of the worst cyanobacteria blooms experienced by Lake Erie in several decades. These blooms form when there is an abundance of macronutrients, such as nitrogen and phosphorous (often from agricultural runoff), sunlight, and warm water. Cyanobacteria blooms in Lake Erie typically accompany favorable weather throughout the summer, with a peak in September. Toxic cyanobacteria, such as the Microcystis thought to be pervasive in Figure 9, can lead to fish kills and affect the safety of water for both recreation and consumption. NASA and partner agencies now use satellite ocean color data as part of early warning indicators for harmful algal blooms in fresh water, with the goal of informing environmental and water quality managers.

\section{Conclusions and Future Directions}

Four decades of satellite ocean color measurements have confirmed many ideas put forth long before satellites existed. But, the synoptic view from space additionally placed these theories into the larger context of Earth's global ecology. In essence, the continuous data record of satellite ocean color has allowed researchers to assess and monitor Earth's living oceans on both a global scale and in near-real time. Major findings or confirmations realized with satellite ocean color instruments relate to:

- the estimation of global primary production on seasonal and decadal scales; 
- the sensitivity of the biologically productive ocean to vertical mixing, including verification of general Sverdrup / Riley concepts (that is, a combination of vertical mixing and light penetration affects the temporal appearance of phytoplankton in the ocean);

- the coupling between ocean climate and primary production (i.e., linkages between biological production, associated carbon fixation, and climate);

- the impact of sunlight absorption by phytoplankton on the ocean's heat budget;

- identification and tracking of ocean and coastal fronts; and,

- improved understanding of the interaction between coastal and oceanic waters;

Looking forward, the satellite ocean color satellite community will move towards advanced instruments with finer spectral and spatial resolution, improved calibration and characterization, and placement in a geostationary orbit, all of which will enable pursuit of new science questions on phytoplankton community composition, carbon fluxes and export, and ocean-land-atmosphere interactions. The NASA Plankton, Aerosol, Cloud, ocean Ecosystem (PACE) mission, scheduled to launch in 2022, for example, will provide the first global (two-day, $1-\mathrm{km}^{2}$ at nadir) spectrometer, as well as multi-angle polarimetry. This spectrometer will provide continuous 5-nm resolution from the ultraviolet to near-infrared, plus several discrete shortwave infrared channels that will improve atmospheric corrections in turbid waters. This continuous, "hyperspectral" resolution will substantially improve the information content for bio-optical algorithms (e.g., inversion of Eqs. [2-4]), enabling, for example, improved derivation of phytoplankton community structure. Similar spectrometers are expected to be pursued on other missions with either reduced temporal coverage and finer spatial footprints or placement in geostationary orbits. Multi-angle polarimetry will complement and add information content to these data by providing novel information on the polarized components of the measured light at five or more viewing angles per ground pixel.

Ultimately, satellite ocean color remote sensing combines a broad spectrum of science and technology. The CZCS demonstrated that the technique could work; however, to advance the state of the art to a degree of sophistication and accuracy required for global change research, many improvements in satellite sensor technology, atmospheric and oceanic radiative transfer modeling, field observation methodologies, calibration metrology, and other areas have been realized over four decades and continue to evolve. It is the intention of the international ocean science community, working with the various space agencies, to develop a continuous longterm global-time series of highly accurate and well-documented satellite ocean color observations - that is, climate data records - which will enable periodic reprocessing of the time series and an unambiguous interpretation of the results. 


\section{Synopsis}

542

543 Satellite ocean color instruments routinely provide global, synoptic views of the Earth's marine

544 biosphere. These space-borne radiometers measure light exiting the top-of-the-atmosphere at

545 discrete wavelengths in the ultraviolet to shortwave infrared region of the spectrum. This

546 includes measurements of the color of the ocean - information used to infer the contents of the

547 sunlit upper ocean, such as concentrations of phytoplankton, suspended sediments, and

548 dissolved organic carbon. Continuous marine biological, ecological, and biogeochemical data

549 records from satellite ocean color instruments now span over twenty years. This time-series

550 not only supports Earth system and climate research, but also ecosystem and watershed

551 management activities, including detection of nuisance and harmful algal blooms.

552

553 


$\begin{array}{ll}554 & \text { Keywords } \\ 555 & \\ 556 & \text { Atmospheric correction } \\ 557 & \text { Biogeochemistry } \\ 558 & \text { Biosphere } \\ 559 & \text { Chlorophyll } \\ 560 & \text { Climate change } \\ 561 & \text { Harmful algae } \\ 562 & \text { Marine ecosystems } \\ 563 & \text { NASA } \\ 564 & \text { Ocean color } \\ 565 & \text { Oceanography } \\ 566 & \text { Phytoplankton } \\ 567 & \text { Primary production } \\ 568 & \text { Radiative transfer } \\ 569 & \text { Remote sensing } \\ 570 & \text { Satellite oceanography } \\ 571 & \\ 572 & \end{array}$




\section{Relevant Web sites}

574

575 International Ocean Colour Coordinating Group, http://ioccg.org

576 NASA Ocean Color Web, https://oceancolor.gsfc.nasa.gov

577 NASA PACE Mission, https://pace.gsfc.nasa.gov

578 NASA EARTHDATA, https://earthdata.nasa.gov

579 U.S. National Research Council report on ocean color, https://doi.org/10.17226/13127

580 Ocean Optics Web Book, http://www.oceanopticsbook.info

581

582

583

584 
Dr. Jeremy Werdell is an Oceanographer in the Ocean Ecology Laboratory (OEL) at NASA Goddard Space Flight Center. He received his Bachelors of Arts in Biology and in Environmental Science from the University of Virginia in 1996, his Masters of Science in Oceanography from the University of Connecticut in 1998, and his Doctor of Philosophy from the University of Maine in 2014. Dr. Werdell has worked in the OEL Ocean Biology Processing Group since 1999, where he now serves as the Project Scientist for the Plankton, Aerosol, Cloud, ocean Ecosystem (PACE) mission, as well as senior leader of several tasks. His interests extend to the on-orbit calibration of ocean color satellite instruments, the validation of remotely-sensed data products, the collection and analysis of in situ biogeochemical oceanographic measurements, and the assimilation of the above to study how the global ocean and various regional ecosystems are changing with time. Dr. Werdell also moonlights as a teacher and student mentor. He has led several internationally attended workshops on bio-optical algorithm development, serves as a member of domestic and international science teams, and helps instruct undergraduate and graduate-level courses on ocean optics and biology.

Dr. Charles McClain received his Bachelors of Science in Physics from William Jewell College in 1970 and his Doctor of Philosophy from North Carolina State University in 1976. He worked at NASA Goddard Space Flight Center for 36 years (1978-2014) where his research focused on the application of satellite ocean color data in studying the linkages between biological and physical processes and the marine carbon cycle beginning with the Coastal Zone Color Scanner. Also, early work included some of the first validation studies of satellite altimetric estimates of significant wave height. He served in various leadership positions including the Sea-viewing Wide Field-of-view Sensor, the Moderate Resolution Imaging Spectroradiometer, the Sensor Intercalibration and Merger for Biological and Interdisciplinary Oceanic Studies, the VisibleInfrared Imaging Radiometer Suite and the Aerosol, Cloud, and Ecology programs. He was the principal investigator in the development of the Ocean Radiometer for Carbon Assessment, a prototype of an advanced satellite ocean color sensor, which was subsequently selected for the Plankton, Aerosol, Cloud and ocean Ecology (PACE) mission. He is presently serving on the 


\begin{tabular}{|c|c|c|}
\hline Symbol & Description & Units \\
\hline$a$ & Absorption coefficient & $\mathrm{m}^{-1}$ \\
\hline$a_{C D O M}$ & Absorption coefficient for colored dissolved organic matter & $\mathrm{m}^{-1}$ \\
\hline$a_{\text {NAP }}$ & Absorption coefficient for non-algal particles & $\mathrm{m}^{-1}$ \\
\hline$a_{p h}$ & Absorption coefficient for phytoplankton & $\mathrm{m}^{-1}$ \\
\hline$a_{w}$ & Absorption coefficient for seawater & $m^{-1}$ \\
\hline$b_{b}$ & Backscattering coefficient & $m^{-1}$ \\
\hline$b_{b, N A P}$ & Backscattering coefficient for non-algal particles & $\mathrm{m}^{-1}$ \\
\hline$b_{b, p h}$ & Backscattering coefficient for phytoplankton & $\mathrm{m}^{-1}$ \\
\hline$b_{b, w}$ & Backscattering coefficient for seawater & $\mathrm{m}^{-1}$ \\
\hline [Chla] & Concentration of chlorophyll-a & $\mathrm{mg} \mathrm{m}^{-3}$ \\
\hline$E_{d}$ & Downwelling irradiance & 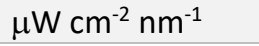 \\
\hline$E_{u}$ & Upwelling irradiance & 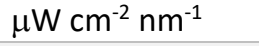 \\
\hline$f$ & Factor that relates $R$ to $a$ and $b_{b}$ & unitless \\
\hline$F_{0}$ & Solar irradiance & 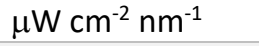 \\
\hline$K_{d}$ & Diffuse attenuation coefficient of downwelling irradiance & $\mathrm{m}^{-1}$ \\
\hline$K_{L u}$ & Diffuse attenuation coefficient of upwelling radiance & $\mathrm{m}^{-1}$ \\
\hline$L_{a}$ & Aerosol radiance & 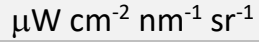 \\
\hline$L_{f}$ & Foam (white cap) radiance & $\mu \mathrm{W} \mathrm{cm}^{-2} \mathrm{~nm}^{-1} \mathrm{sr}^{-1}$ \\
\hline$L_{g}$ & Sun glint radiance & $\mu \mathrm{W} \mathrm{cm}^{-2} \mathrm{~nm}^{-1} \mathrm{sr}^{-1}$ \\
\hline$L_{r}$ & Rayleigh radiance & $\mu \mathrm{W} \mathrm{cm}^{-2} \mathrm{~nm}^{-1} \mathrm{sr}^{-1}$ \\
\hline$L_{r a}$ & Rayleigh-aerosol interaction radiance & 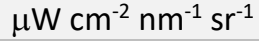 \\
\hline$L_{t}$ & Total radiance observed by the space-borne instrument & $\mu \mathrm{W} \mathrm{cm}^{-2} \mathrm{~nm}^{-1} \mathrm{sr}^{-1}$ \\
\hline$L_{u}$ & Upwelling radiance & 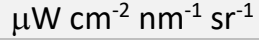 \\
\hline$L_{w}$ & Water-leaving radiance & $\mu \mathrm{W} \mathrm{cm}^{-2} \mathrm{~nm}^{-1} \mathrm{sr}^{-1}$ \\
\hline$L_{w n}$ & Normalized water-leaving radiance & $\mu \mathrm{W} \mathrm{cm}^{-2} \mathrm{~nm}^{-1} \mathrm{sr}^{-1}$ \\
\hline$n$ & Index of refraction & unitless \\
\hline$Q$ & Factor that relates $L_{u}$ to $E_{u}$ & $\mathrm{sr}$ \\
\hline$R$ & Reflectance & unitless \\
\hline$R_{r s}$ & Remote-sensing reflectance & $s r^{-1}$ \\
\hline$\rho$ & Fresnel reflectance & unitless \\
\hline$t$ & Diffuse transmittance & unitless \\
\hline$T$ & Direct transmittance & unitless \\
\hline
\end{tabular}


Bailey, S. W., and P. J. Werdell (2006), A multi-sensor approach for the on-orbit validation of ocean color satellite data products, Remote Sensing of Environment, 102, 12-23, doi:10.1016/j.rse.2006.01.015.

Clark, D. K., H. R. Gordon, K. J. Voss, Y. Ge, W. W. Broenkow, and C. Trees (1997), Validation of atmospheric correction over the oceans, Journal of Geophysical Research: Atmospheres, 102,

631 Donlon, C., A. Parr, and G. Zibordi (2014), Optical Radiometry for Ocean Climate Measurements, 632722 pp., Academic Press.

633 Eplee, R. E., G. Meister, F. S. Patt, B. A. Franz, S. W. Bailey, and C. R. McClain (2013), The on634 orbit calibration of SeaWiFS, Applied Optics, 51, 8702-8370, doi:10.1364/A0.51.008702.

635 Feldman, G., et al. (1989), Ocean color: Availability of the global data set, EOS Transactions 636 AGU, 70, 634-641, doi:10.1029/89E000184.

637 Franz, B. A., S. W. Bailey, P. J. Werdell, and C. R. McClain (2007), Sensor-independent approach 638 to the vicarious calibration of satellite ocean color radiometry, Applied Optics, 46, 5068-5082, 639 doi:doi.org/10.1364/AO.46.005068.

640 Gordon, H. R., and A. Morel (1983), Remote Assessment of Ocean Color for Interpretation of 641 Satellite Visible Imagery, 106 pp., Springer-Verlag.

642 IOCCG (2008), Why Ocean Colour? The Societal Benefits of Ocean-Colour Technology, 147 pp., 643 IOCCG, Dartmouth, Canada.

644 IOCCG (2009), Remote Sensing in Fisheries and Aquaculture, 128 pp., IOCCG, Dartmouth, 645 Canada.

646 IOCCG (2012), Mission Requirements for Future Ocean-Colour Sensors, 115 pp., IOCCG, 647 Dartmouth, Canada.

648 IOCCG (2014), Phytoplankton Functional Types from Space, 164 pp., IOCCG, Dartmouth, Canada.

649 Kirk, J. T. O. (2011), Light and Photosynthesis in Aquatic Ecosystems, 662 pp., Cambridge 650 University Press.

651 Martin, S. (2014), An Introduction to Ocean Remote Sensing, 521 pp., Cambridge University 652 Press.

653 McClain, C. R. (2009), A Decade of Satellite Ocean Color Observations, Annual Review of Marine 654 Science, 1, 19-42, doi:10.1146/annurev.marine.010908.163650. 
655 Meister, G., B. A. Franz, E. J. Kwiatkowska, and C. R. McClain (2012), Corrections to the 656 Calibration of MODIS Aqua Ocean Color Bands derived from SeaWiFS Data, IEEE Transactions on 657 Geoscience and Remote Sensing, 50, 310-319, doi:10.1109/TGRS.2011.2160552.

658 Mobley, C. D. (1994), Light and Water: Radiative Transfer in Natural Waters, 592 pp., Academic 659 Press.

660 Mobley, C. D., J. Werdell, B. Franz, Z. Ahmad, and S. Bailey (2016), Atmospheric Correction for 661 Satellite Ocean Color Radiometry, 85 pp., NASA Goddard Space Flight Center.

662 Morel, A., and L. Prieur (1977), Analysis of variations in ocean color, Limnology and 663 Oceanography, 22, 709-722, doi:10.4319/lo.1977.22.4.0709.

664 O'Reilly, J. E., S. Maritorena, B. G. Mitchell, D. A. Siegel, K. L. Carder, S. A. Garver, M. Kahru, and 665 C. R. McClain (1998), Ocean color chlorophyll algorithms for SeaWiFS, Journal of Geophysical 666 Research: Oceans, 103, 24937-24953, doi:10.1029/98JC02160

667 PACE Science Definition Team (2018), Pre-Aerosols, Clouds, and ocean Ecosystem (PACE)

668 Mission Science Definition Team Report, 316 pp., NASA Goddard Space Flight Center.

669 Robinson, I. S. (2004), Measuring the Oceans from Space, 670 pp., Springer-Verlag.

670 Werdell, P. J., S. W. Bailey, B. A. Franz, L. W. Harding Jr., G. C. Feldman, and C. R. McClain 671 (2009), Regional and seasonal variability of chlorophyll-a in Chesapeake Bay as observed by 672 SeaWiFS and MODIS-Aqua, Remote Sensing of Environment, 113, 1319-1330, 673 doi:10.1016/j.rse.2009.02.012.

674 Werdell, P. J., et al. (2018), An overview of approaches and challenges for retrieving marine 675 inherent optical properties from ocean color remote sensing, Progress in Oceanography, 160, 676 186-212, doi:10.1016/j.pocean.2018.01.001. 